\title{
ANÁLISIS TECNOLÓGICO DE OBJETOS LAPIDARIOS DE LA SALA MEXICA DENTRO DE LA BÓVEDA DEL MUSEO NACIONAL DE ANTROPOLOGÍA, MÉXICO
}

\author{
Technological analysis of lapidary objects from de Mexica Collection inside the Vault of the \\ National Museum of Anthropology
}

Reyna Beatriz Solís Ciriaco ${ }^{1}$, Emiliano Ricardo Melgar Tísoc ${ }^{2}$ y Bertina Olmedo Vera ${ }^{3}$

https://doi.org/10.15366/baexuam2020.14.003

\begin{abstract}
Resumen
El Museo Nacional de Antropología de México resguarda una de las colecciones de objetos arqueológicos más grandes e importantes de distintas culturas, zonas y épocas del México prehispánico. Dicho museo está dividido en 11 salas, siendo la Sala Mexica la más grande de todas y se encuentra ubicada en la parte central del recorrido. Sin embargo, son pocos los estudios arqueométricos enfocados en conocer las técnicas de manufactura de los materiales mexicas en este recinto cultural, en especial los objetos lapidarios. Por ello, desde el 2019 se inició la revisión y análisis tecnológico de la lapidaria de la Sala Mexica, empezando con las piezas resguardadas en la Bóveda de Seguridad del Museo Nacional de Antropología procedentes de Tlatelolco, El Volador y Azcapotzalco. Para ello se empleó arqueología experimental y la caracterización de huellas de manufactura con microscopía óptica y electrónica de barrido. De esta manera se pudieron identificar los materiales e instrumentos de trabajo empleados en su elaboración y las semejanzas o diferencias entre los sitios, así como rastrear su filiación cultural local o foránea.
\end{abstract}

Palabras clave: Arqueología experimental, huellas de manufactura, mexicas, lapidaria.

\begin{abstract}
The National Museum of Anthropology in Mexico City safeguards one of the largest and most important collections of archaeological objects from different cultures, areas and periods of preHispanic Mexico. This museum is divided into 11 exhibit halls, with the Mexica Hall being the largest of all and is located in the central part of the tour. However, the archaeometric studies focused on knowing the manufacturing techniques of Mexican materials are scarce in this cultural precinct, especially on lapidary objects. Therefore, since 2019 we performed the technological analysis of the lapidary items of the Mexica Hall collection, starting with the pieces stored in the Security Vault from Tlatelolco, El Volador and Azcapotzalco. Experimental archaeology and the characterization of manufacturing traces with optical microscopy and scanning electronics were used for this purpose. By this way, we could identify the materials and working instruments used in their elaboration and the similarities or differences between the sites, as well as tracking their local or foreign cultural affiliations.
\end{abstract}

Key words: Experimental archaeology, manufacturing traces, Mexica, lapidary.

\footnotetext{
${ }^{1}$ Museo del Templo Mayor. ORCID: 0000-0002-6719-0772. reynabsolis@hotmail.com

${ }^{2}$ Museo del Templo Mayor. ORCID: 0000-0002-7300-3224. anubismarino@ gmail.com

${ }^{3}$ Museo Nacional de Antropología. ORCID: 0000-0002-7739-9254. pitirijas0518@yahoo.com.mx
} 


\section{INTRODUCCIÓN}

Como parte de los trabajos de investigación del proyecto "Estilo y tecnología de los objetos lapidarios en el México Antiguo" con sede en el Museo del Templo Mayor, desde el 2019 inició el estudio de materiales lapidarios de la curaduría de la Sala Mexica del Museo Nacional de Antropología. Esta colaboración ha permitido que las piezas lapidarias de ese acervo puedan analizarse de forma sistemática para conocer con mayor detalle las características tecnológicas que presentan. Para llevar a cabo lo anterior, se ha empleado la arqueología experimental y la caracterización de huellas de manufactura con microscopía óptica y electrónica de barrido en colecciones de varios sitios y colecciones de México, lo cual nos ha permitido identificar patrones de manufactura y diferenciar estilos y tradiciones regionales y temporales con mayores argumentos que la simple morfología o su parecido (Melgar et al., 2018).

Ponemos énfasis en el aspecto de la manufactura de los objetos lapidarios y las preferencias culturales por determinados materiales, ya que no sólo la predilección por ciertos artefactos y materias primas sino también sus técnicas de elaboración son expresiones del estilo (Lechtman, 1975:6-7). Estos detalles tecnológicos y las distintas trayectorias de producción, circulación y distribución de objetos preciosos se entrelazan con otros ámbitos sociales (Hodder, 2016:115116). Así, en el estudio de los materiales arqueológicos es necesario considerar la tecnología cuando se trata de asignarles filiaciones culturales y/o temporalidades. A partir de ello, en este estudio se propone que el empleo de la arqueología experimental y el análisis de las huellas de manufactura son importantes porque permiten identificar la homogeneidad o heterogeneidad de las piezas atribuidas a un estilo y su probable pertenencia a él, así como distinguir las producciones locales de las foráneas en un sitio y región (Melgar, 2014). Además, este tipo de análisis también permite evaluar la filiación cultural de objetos de forma geométrica y no solamente de piezas antropomorfas o que por su iconografía se les ha asignado un estilo, ya que, si comparten materias primas particulares o patrones de manufactura específicos con colecciones lapidarias de determinadas culturas, áreas o asentamientos, se puede postular su pertenencia a dicha tradición artesanal o estilo tecnológico.

Con base en ello, durante la revisión y análisis del material se determinaron las modificaciones tecnológicas presentes en los objetos para compararlas y contrastarlas con los experimentos realizados en el "Taller de Arqueología Experimental en lapidaria" con sede en el Museo del Templo Mayor. Posteriormente se realizó el análisis tipológico y tecnológico. Finalmente se hicieron algunas interpretaciones preliminares en cuanto a los procesos de manufactura de los objetos lapidarios y su probable filiación cultural. 
R.B. Solís Ciriaco, E. R. Melgar Tísoc y B. Olmedo Vera. Análisis tecnológico de objetos lapidarios de la sala mexica dentro de la bóveda del Museo Nacional de Antropología, México.

\section{Materiales lapidarios analizados}

El material analizado fue recuperado en Tlatelolco, Azcapotzalco y El Volador (Fig. 1), el cual se encuentra en la Bóveda del Museo Nacional de Antropología. Las características de estos materiales fueron los siguientes:
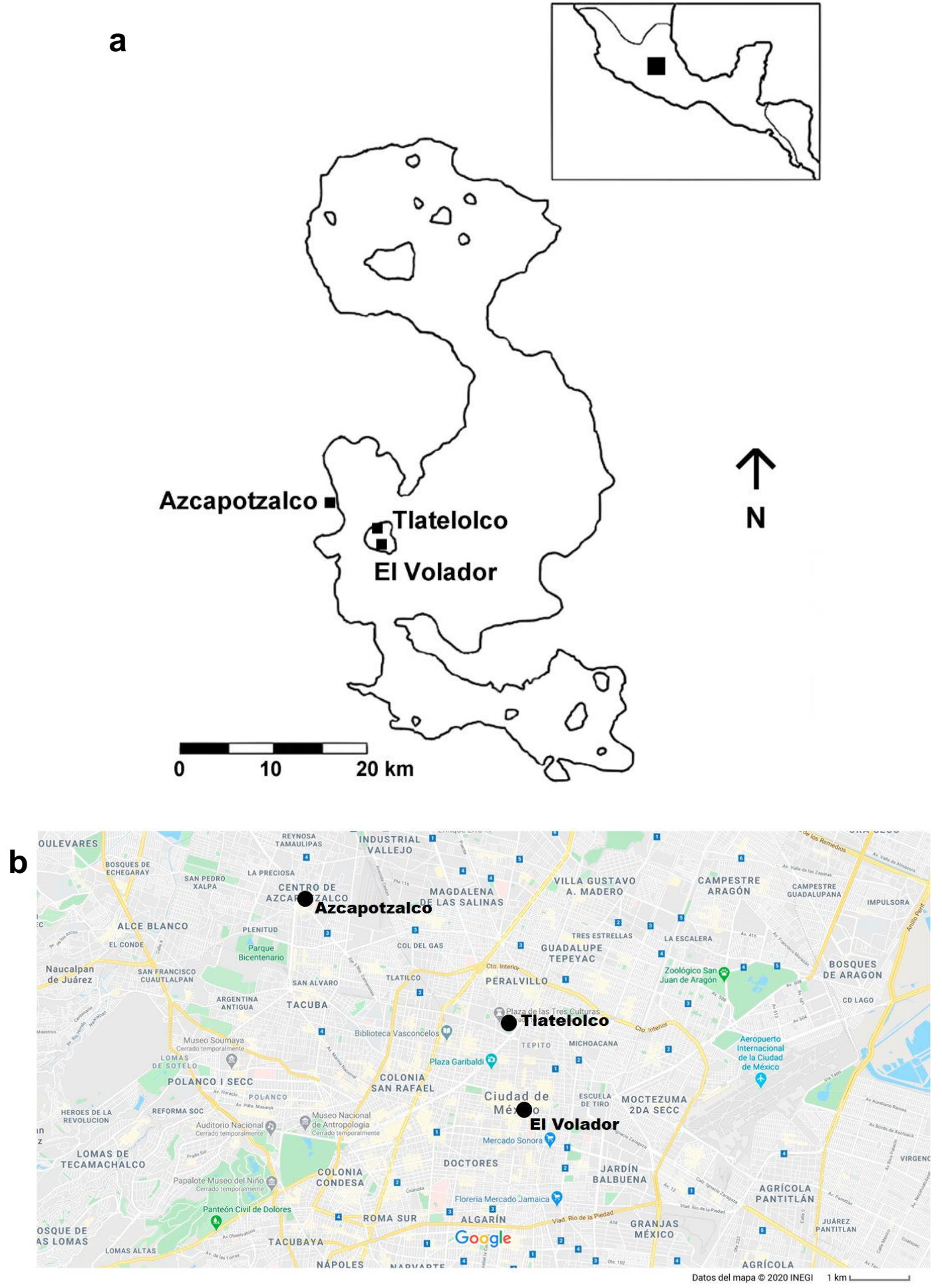

Figura 1. Localización de los sitios de donde proceden las piezas analizadas: plano con el Lago de Texcoco en el siglo XVI (a) y mapa del INEGI actual de la zona urbana de la Ciudad de México (b). Dibujo de Emiliano Melgar (a) y Mapa del INEGI, 2020 (b). 


\subsection{Lapidaria de Tlatelolco}

Consiste en ocho piezas completas de piedra verde, una plomada, un pulidor y cuatro cuentas, cuya clasificación tipológica fue la siguiente (Tabla 1 y Fig. 2):

\begin{tabular}{|c|c|c|c|c|c|c|c|c|}
\hline \multicolumn{9}{|c|}{ Tabla 1. Lapidaria de Tlatelolco analizada } \\
\hline Tipo & Forma & Caras & Paredes & Perforada & Forma & Lugar & $\begin{array}{c}\text { Medidas }(\mathrm{cm}) \\
\text { L; A; E }\end{array}$ & $\mathrm{C} / \mathrm{F}$ \\
\hline Plomada & Oval & Convexas & Convexas & No & - & - & $5.34 ; 3.4 ; 3.15$ & $1 / 0$ \\
\hline Pulidor & Esférica & Convexas & Convexas & No & - & - & $2.3 ; 2.09 ; 1.69$ & $1 / 0$ \\
\hline \multirow[t]{3}{*}{ Cuenta } & \multirow[t]{2}{*}{ Rueda } & $\begin{array}{c}1 \text { plana } \\
1 \text { oblicua }\end{array}$ & Convexas & Sí & Bicónica & Centro & $\begin{array}{l}1.02-3.34 ; 1.02- \\
3.34 ; 0.73-2.33\end{array}$ & $4 / 0$ \\
\hline & & $\begin{array}{c}1 \text { plana } \\
1 \\
\text { convexa }\end{array}$ & Convexas & Sí & Bicónica & Centro & $2.92 ; 2.92 ; 1.71$ & $1 / 0$ \\
\hline & Tabular & $\begin{array}{c}1 \text { plana } \\
1 \text { oblicua }\end{array}$ & Convexas & Sí & Tubular & Centro & $2.73 ; 1.68 ; 3.28$ & $1 / 0$ \\
\hline \multicolumn{8}{|c|}{ Total } & $8 / 0$ \\
\hline
\end{tabular}

PV: Piedra verde; C/F:Completos/Fragmentos; L: Largo; A: Ancho; E: Espesor

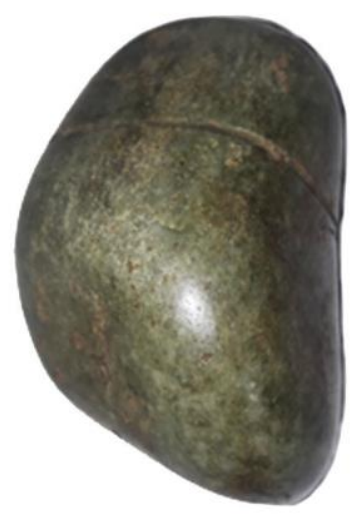

a

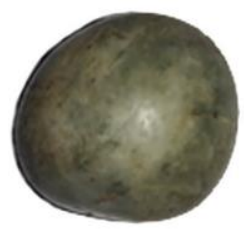

b
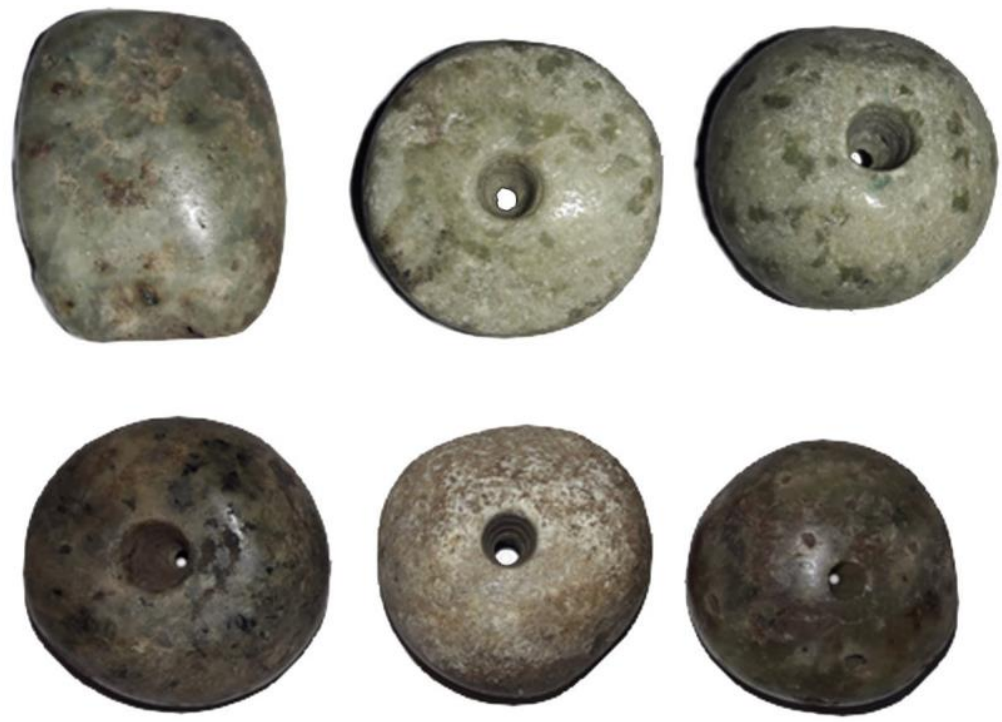

C

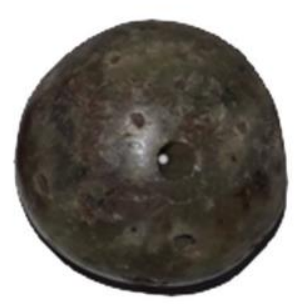

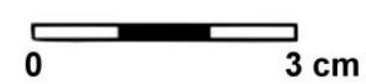

Figura 2. Lapidaria de Tlatelolco: plomada (a), pulidor (b) y cuentas (c). Fotografía de Reyna Solís. 
R.B. Solís Ciriaco, E. R. Melgar Tísoc y B. Olmedo Vera. Análisis tecnológico de objetos lapidarios de la sala mexica dentro de la bóveda del Museo Nacional de Antropología, México.

\subsection{Lapidaria de El Volador}

Consiste en siete piezas de piedra verde, de las cuales seis son cuentas y una es un pendiente (Tabla 2 y Fig. 3).

\begin{tabular}{|c|c|c|c|c|c|c|c|c|}
\hline \multicolumn{9}{|c|}{ Tabla 2. Lapidaria de El Volador analizada } \\
\hline Tipo & Forma & Caras & Paredes & Perforada & Forma & Lugar & $\begin{array}{c}\text { Medidas (cm) } \\
\text { L; A; E }\end{array}$ & $\mathrm{C} / \mathrm{F}$ \\
\hline \multirow[t]{5}{*}{ Cuenta } & Rueda & $\begin{array}{c}1 \text { plana } \\
1 \text { oblicua }\end{array}$ & Convexas & Sí & Bicónica & Centro & $\begin{array}{l}1.73-2.3 ; 1.73- \\
2.3 ; 1.47-1.66\end{array}$ & $2 / 0$ \\
\hline & Tubular & $\begin{array}{l}1 \text { plana } \\
1 \text { oblicua }\end{array}$ & Convexas & Sí & Bitubular & Centro & $1.6 ; 1.41 ; 3.77$ & $1 / 0$ \\
\hline & Cilindro & $\begin{array}{c}1 \text { plana } \\
1 \text { oblicua }\end{array}$ & Convexas & Sí & Tubular & Centro & $1.2 ; 1.2 ; 1.62$ & $1 / 0$ \\
\hline & Tabular & $\begin{array}{c}1 \text { plana } \\
1 \text { oblicua }\end{array}$ & Convexas & Sí & Bitubular & Centro & $\begin{array}{l}1.35-2.4 ; 0.94- \\
1.67 ; 2.34-3.09\end{array}$ & $2 / 0$ \\
\hline & Esférica & Convexas & Convexas & Sí & Bicónica & Centro & $2.24 ; 2.24 ; 1.83$ & $1 / 0$ \\
\hline \multicolumn{8}{|c|}{ Total } & $7 / 0$ \\
\hline
\end{tabular}
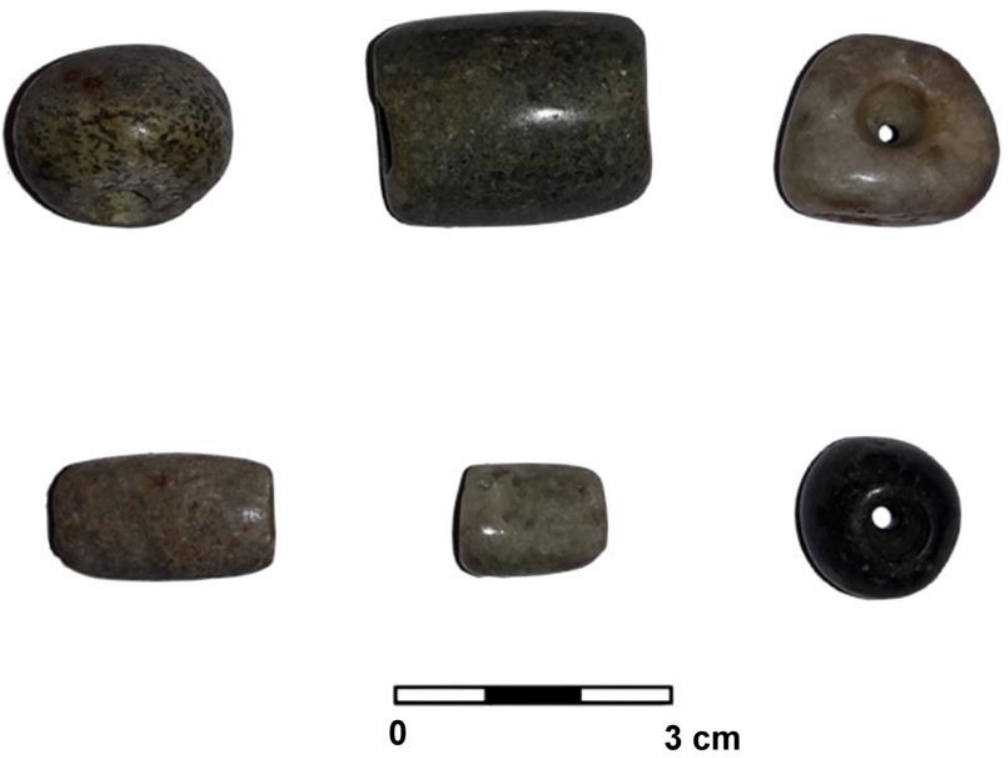

Figura 3. Lapidaria de El volador. Fotografía de Reyna Solís.

\subsection{Lapidaria de Azcapotzalco}

Consta de cinco cuentas tipo rueda, dos tiene tonalidades verdes con negro, otra es color crema con vetas y dos son de tonalidad café (Tabla 3 y Fig. 4). 


\begin{tabular}{|c|c|c|c|c|c|c|c|c|}
\hline Tipo & Forma & Caras & Paredes & Perforada & Forma & Lugar & $\begin{array}{c}\text { Medidas (cm) } \\
\text { L; A; E }\end{array}$ & $\mathrm{C} / \mathrm{F}$ \\
\hline \multirow[t]{2}{*}{ Cuenta } & \multirow[t]{2}{*}{ Rueda } & $\begin{array}{c}1 \text { plana } \\
1 \text { oblicua }\end{array}$ & Convexas & Sí & Bicónica & Centro & $\begin{array}{l}1.39-2.21 ; 1.39- \\
2.21 ; 1.04-1.77\end{array}$ & $4 / 0$ \\
\hline & & Planas & Convexas & Sí & Bicónica & Centro & $1.67 ; 1.67 ; 1.05$ & $1 / 0$ \\
\hline \multicolumn{8}{|c|}{ Total } & $5 / 0$ \\
\hline
\end{tabular}
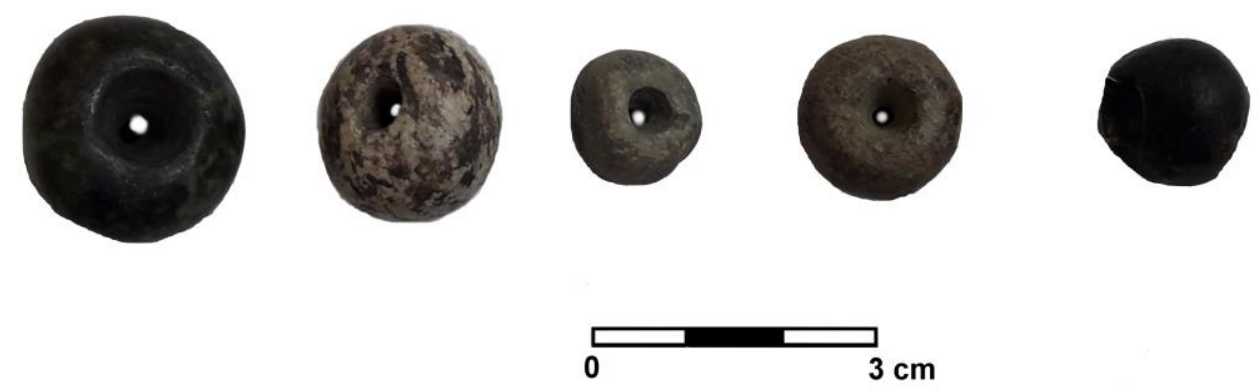

Figura 4. Lapidaria de Azcapotzalco. Fotografía de Reyna Solís.

Si bien estos objetos lapidarios que se analizaron son pocos, resulta interesante que, a diferencia de otras colecciones revisadas procedentes de la Cuenca de México, destaca la presencia casi en su totalidad de cuentas de piedra verde y tonalidades oscuras, las cuales, al realizarles los distintos estudios presentan una estandarización en sus formas, pero no en su tecnología, lo que nos sugiere que muy probablemente sus zonas de manufactura pueden ser diversas.

\section{Análisis tecnológico de las colecciones}

Posterior a la clasificación tipológica se llevó a cabo el análisis de las huellas de manufactura. Para ello nos hemos apoyado en la arqueología experimental. Según dicha corriente, en las sociedades humanas toda actividad se encuentra normada, por lo cual los artefactos son usados o producidos de acuerdo con esquemas determinados, que les proporcionan características específicas. Ello implica que la elaboración o utilización de objetos similares, siguiendo los mismos patrones, dejará rasgos característicos y diferenciables entre sí (Ascher, 1961; Binford, 1991:22; Velázquez, 2007).

Con ello en mente, desde el 2004 se ha desarrollado un taller de arqueología experimental de lapidaria con sede en el Museo del Templo Mayor, en el cual se han reproducido los diferentes tipos de modificaciones que presentan los objetos (Fig. 5). La selección de los materiales e instrumentos empleados en dicho taller se ha hecho con base en la información reportada en diversas fuentes históricas (Durán, 2006; Sahagún, 2006), propuestas de algunos investigadores (Charlton, 1993; Mirambell, 1968) y de datos arqueológicos (Feinman y Nicholas, 1995; Moholy-Nagy, 1997). Así, se han empleado los instrumentos y procesos de trabajo que es posible suponer que fueron utilizados por los distintos pueblos prehispánicos (Tabla 4). 


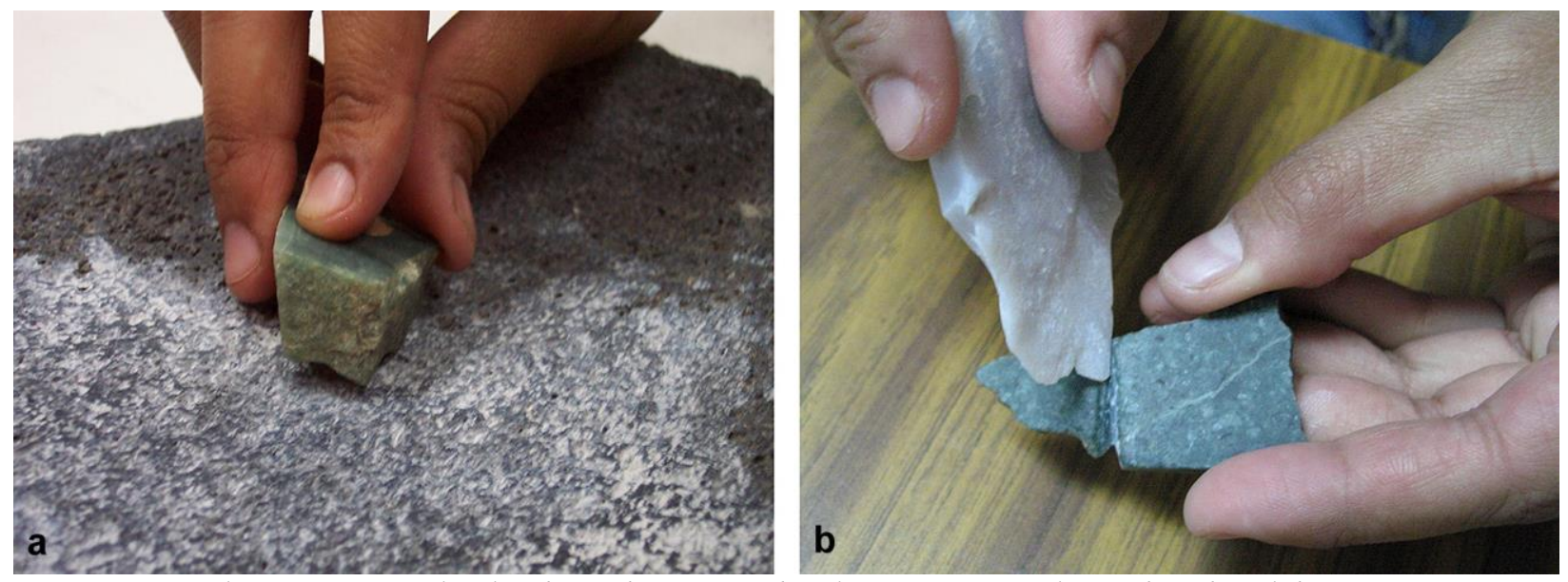

Figura 5. Arqueología experimental en lapidaria: desgaste con basalto (a) y corte con lascas de pedernal (b).

\begin{tabular}{|l|l|}
\hline \multicolumn{2}{|c|}{ Tabla 4. Materiales empleados en cada modificación } \\
\hline \multicolumn{1}{|c|}{ Modificación } & \multicolumn{1}{|c|}{ Materiales } \\
\hline Desgastes de superficies & $\begin{array}{l}\text { Basalto, andesita, dacita, riolita, arenisca, caliza, pizarra y granito, } \\
\text { adicionando agua y ocasionalmente arena. }\end{array}$ \\
\hline Cortes & $\begin{array}{l}\text { Instrumentos líticos de pedernal, obsidiana, pizarra y madera } \\
\text { petrificada. } \\
\text { Arena, agua y tiras de piel o cuerdas vegetales de ixtle y henequén. }\end{array}$ \\
\hline Perforaciones & $\begin{array}{l}\text { Abrasivos (arena, ceniza volcánica, polvo de obsidiana, polvo de } \\
\text { pedernal, polvo de selenita), animados con ramas de carrizo, } \\
\text { adicionando agua. } \\
\text { Instrumentos líticos de pedernal, obsidiana, cuarzo y madera } \\
\text { petrificada. } \\
\text { Espinas de origen animal (puercoespín) y vegetal (biznaga). } \\
\text { Instrumentos de hueso. }\end{array}$ \\
\hline Calados & $\begin{array}{l}\text { Abrasivos (arena, ceniza volcánica, polvo de obsidiana y polvo de } \\
\text { pedernal), animados con ramas de carrizo de gran diámetro y agua. } \\
\text { Instrumentos líticos de pedernal y obsidiana. }\end{array}$ \\
\hline Instrumentos líticos de pedernal y obsidiana. \\
\hline Acabados & $\begin{array}{l}\text { Pulido con abrasivos (arena, ceniza volcánica, polvo de obsidiana, } \\
\text { polvo de pedernal, polvo de cuarzo, hematita), agua y trozos de } \\
\text { piel. } \\
\text { Pulido con nódulos de pedernal, arenisca, jadeíta, hematita y } \\
\text { corindón. } \\
\text { Bruñidos con trozos de piel en seco. La aplicación de ambos } \\
\text { acabados. }\end{array}$ \\
\hline
\end{tabular}

Para realizar los experimentos se diseñó una ficha de registro, en la cual se tomó en cuenta la siguiente información: su número de identificación (consecutivo); nombre del experimento; objetivo; materiales empleados (especificando sus características y medidas); descripción de procedimientos utilizados (dirección y tipo de movimientos); hora de inicio y de conclusión de trabajo; medidas finales del material y observaciones. Durante la ejecución de cada experimento se llevó a cabo su registro fotográfico de manera detallada, desde el momento inicial y los materiales que intervienen, hasta el resultado final o conclusión de la modificación reproducida. 
Una vez realizado cada experimento, las huellas de manufactura resultantes se comparan con las piezas arqueológicas, en los tres niveles de observación establecidos en el proyecto "Estilo y tecnología de los objetos lapidarios en el México Antiguo": macroscópicamente (simple vista), con microscopía estereoscópica (10 y 30x) y con microscopía electrónica de barrido (100x, 300x, 600x y 1000x). Para este último nivel, las micrografías se obtienen empleando los mismos parámetros (10 mm de distancia, haz de $50,20 \mathrm{kV}$ de voltaje y señal de electrones secundarios SEI). Así, se describen las características superficiales observadas en cada huella, como la dirección y tamaño de bandas y líneas, su rugosidad y textura.

Para agilizar el análisis se realizaron réplicas en polímeros. Esta técnica no destructiva ni invasiva tomada de la metalografía ha resultado sumamente útil para obtener superficies que presentan huellas de manufactura. Consiste en un acetato que se reblandece al aplicársele acetona pero que al evaporarse vuelve a recobrar su dureza original. Así, presionando este acetato contra la superficie elegida cuando está reblandecido, se obtiene el negativo de las huellas que quedan fijadas al secarse y endurecerse sin deformarlaslo cual permitió ingresar varias modificaciones a la vez. Con ello pueden obtenerse huellas de piezas que superaran el tamaño de la cámara de muestreo, mayores a diez cm, o de algunas modificaciones de difícil observación, como las paredes internas de las perforaciones. En el caso particular del acervo de la Sala Mexica resguardado en la Bóveda del MNA, el hacer copias de las huellas de manufactura con las réplicas en polímeros permitió analizarlas en el Laboratorio de MEB sin tener que mover las piezas debido a la gran cantidad de trámites y permisos requeridos para ello, reduciendo el tiempo de análisis y evitando largos procesos burocráticos.

De esta manera, fue posible identificar las herramientas empleadas en su manufactura, donde los resultados fueron los siguientes:

\subsection{Tlatelolco}

En el material lapidario de Tlatelolco se aprecian dos patrones tecnológicos, el primero y más frecuente se identificó en la plomada, el pulidor y en cuatro cuentas. Dicho rasgo se caracteriza por el empleo de caliza para desgastar y nódulo de jadeíta para dar acabados. El segundo patrón presente en dos cuentas coincide con el desgaste con andesita y nódulo de pedernal para dar acabados. En ambos patrones se emplea perforador de pedernal.

\subsubsection{Superficies y acabados}

Con microscopía óptica es posible ver una superficie lustrosa con rayones rectos que corren en diferentes direcciones (Fig. 6). 

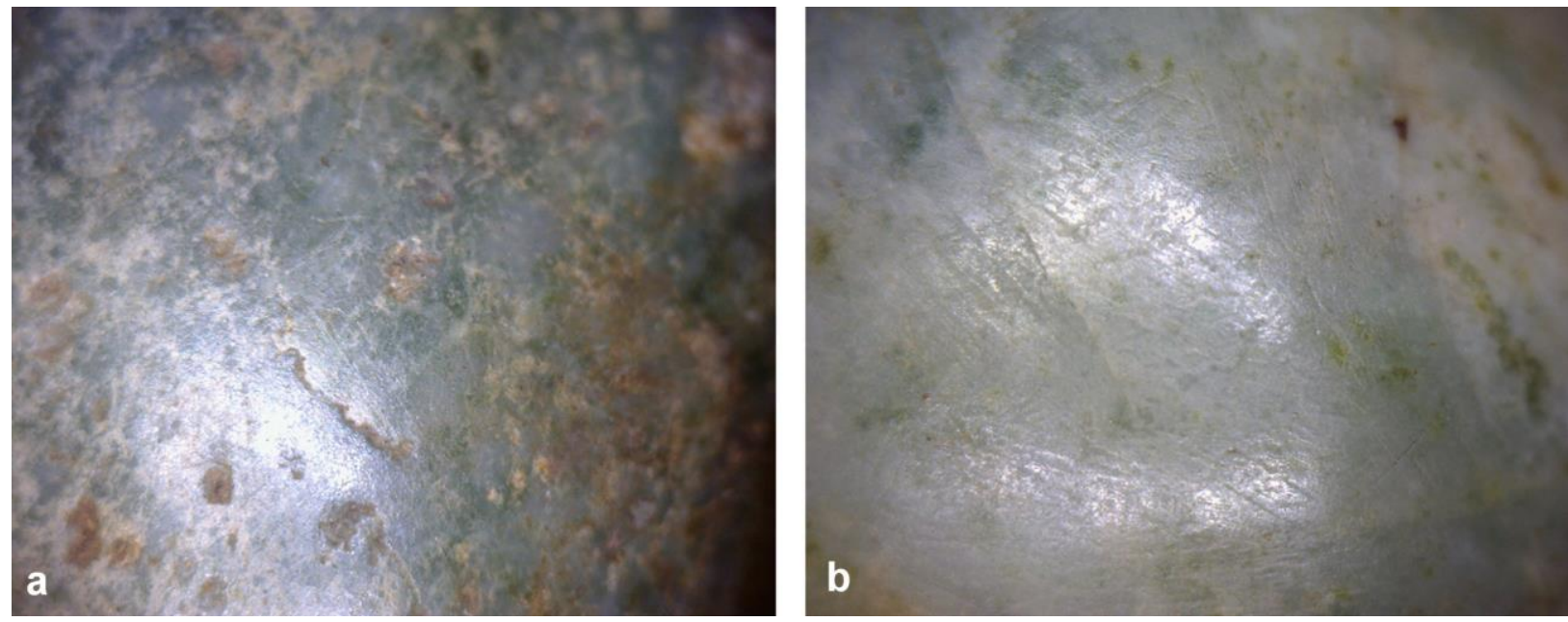

Figura 6. Superficies de plomada (a) y cuenta (b), ambas a 30X.

A mayores amplificaciones en el MEB es posible ver dos rasgos en el material, el primero se identifica a $100 \mathrm{X}$ por la presencia de bandas rectas que corren en diferentes direcciones del orden de las $20 \mu \mathrm{m}$ sobre una superficie un tanto rugosa (Fig. 7a). Dicha característica coincide con el desgaste experimental con caliza (Fig. 7b). A 1000X se pueden ver líneas muy tenues sobre una superficie con partículas (Fig. 7c), estos rasgos coinciden con el uso de pulidor de jadeíta para dar acabados (Fig. 7d).
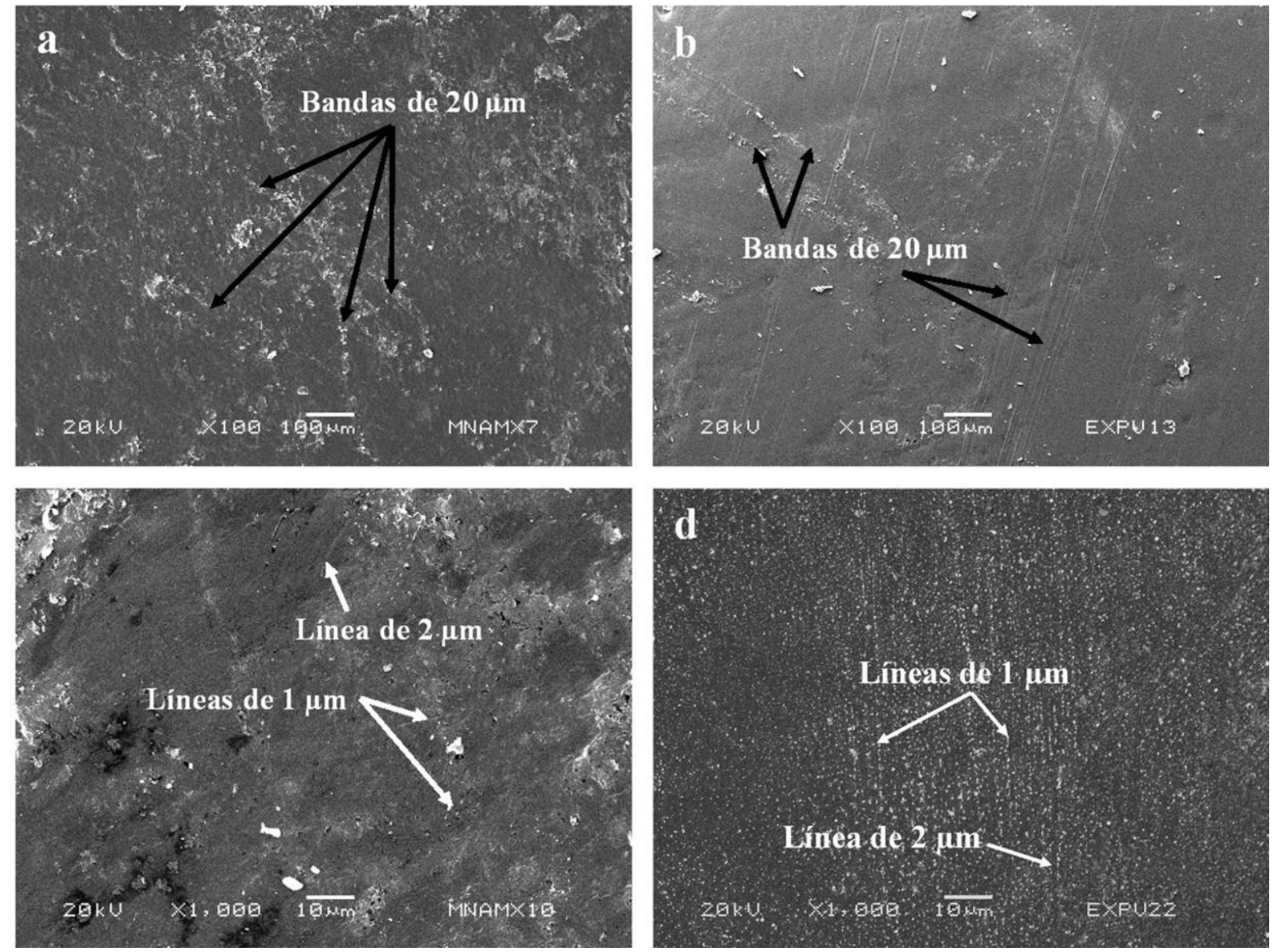

Figura 7. Superficie de cuenta (a), desgaste experimental con caliza (b), acabado de cuenta (c) y pulido experimental con nódulo de jadeíta $(d)$. 
En el segundo patrón correspondiente se detectaron a 100X bandas rectas del orden de las $66 \mu \mathrm{m}$ (Fig. 8a), las cuales coinciden con el desgaste experimental con andesita (Fig. 8b). A 600X es posible distinguir bandas rectas bien marcadas, las cuales corren en diferentes direcciones y que al juntarse crean bandas de un grosor mayor (Fig. 8c). Dicha característica es similar a la que deja el pulido experimental con nódulo de pedernal (Fig. 8d).
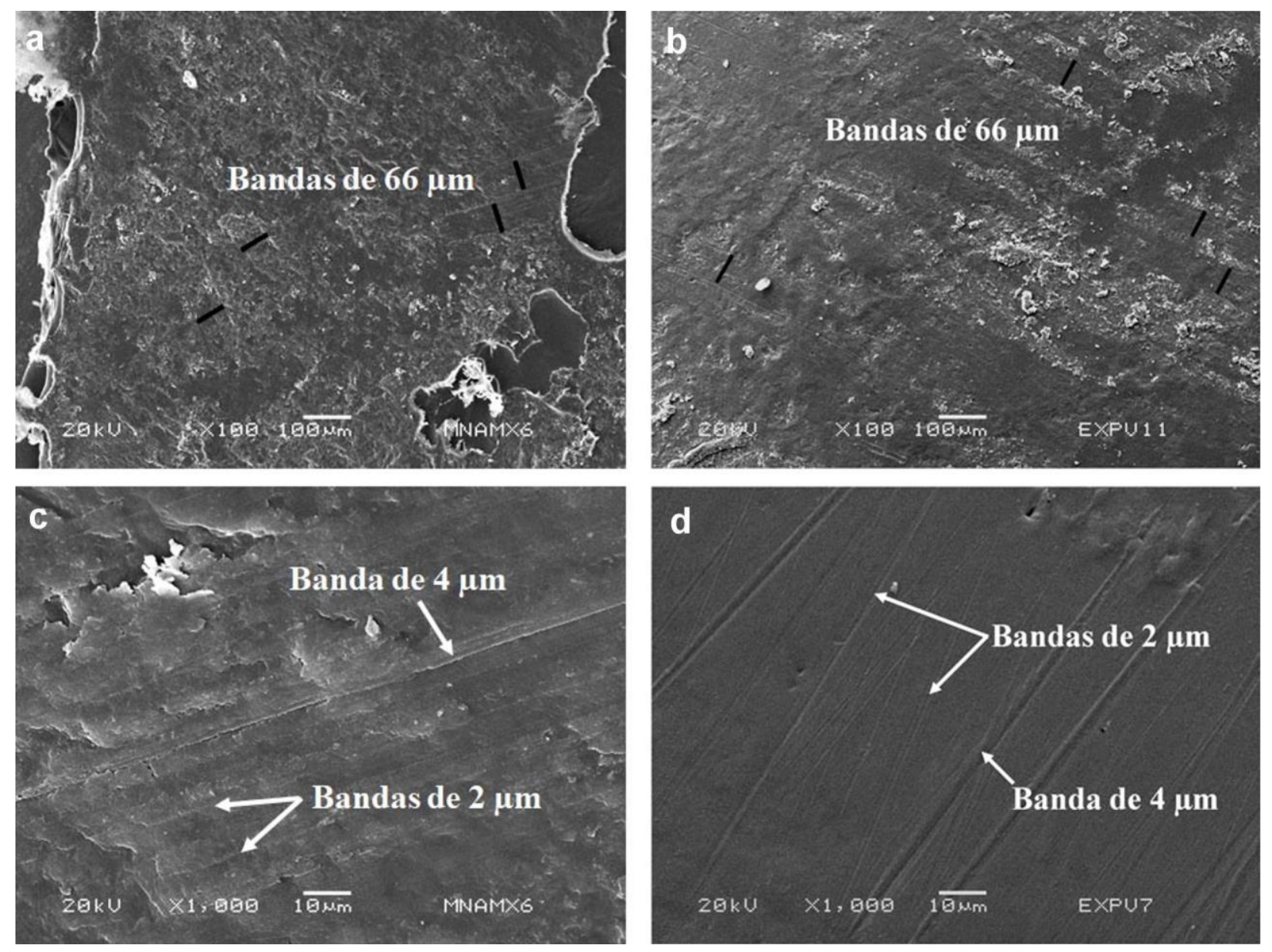

Figura 8. Superficie de cuenta (a), desgaste con andesita (b), acabado de cuenta (c) y pulido con nódulo de pedernal (d).

\subsubsection{Perforaciones}

Con microscopía óptica todas las perforaciones de Tlatelolco tienen círculos concéntricos (Fig. 9a-b), lo cual es evidencia del empleo de instrumentos líticos para realizar las horadaciones (Fig. $9 \mathrm{c}-\mathrm{d})$. 
R.B. Solís Ciriaco, E. R. Melgar Tísoc y B. Olmedo Vera. Análisis tecnológico de objetos lapidarios de la sala mexica dentro de la bóveda del Museo Nacional de Antropología, México.
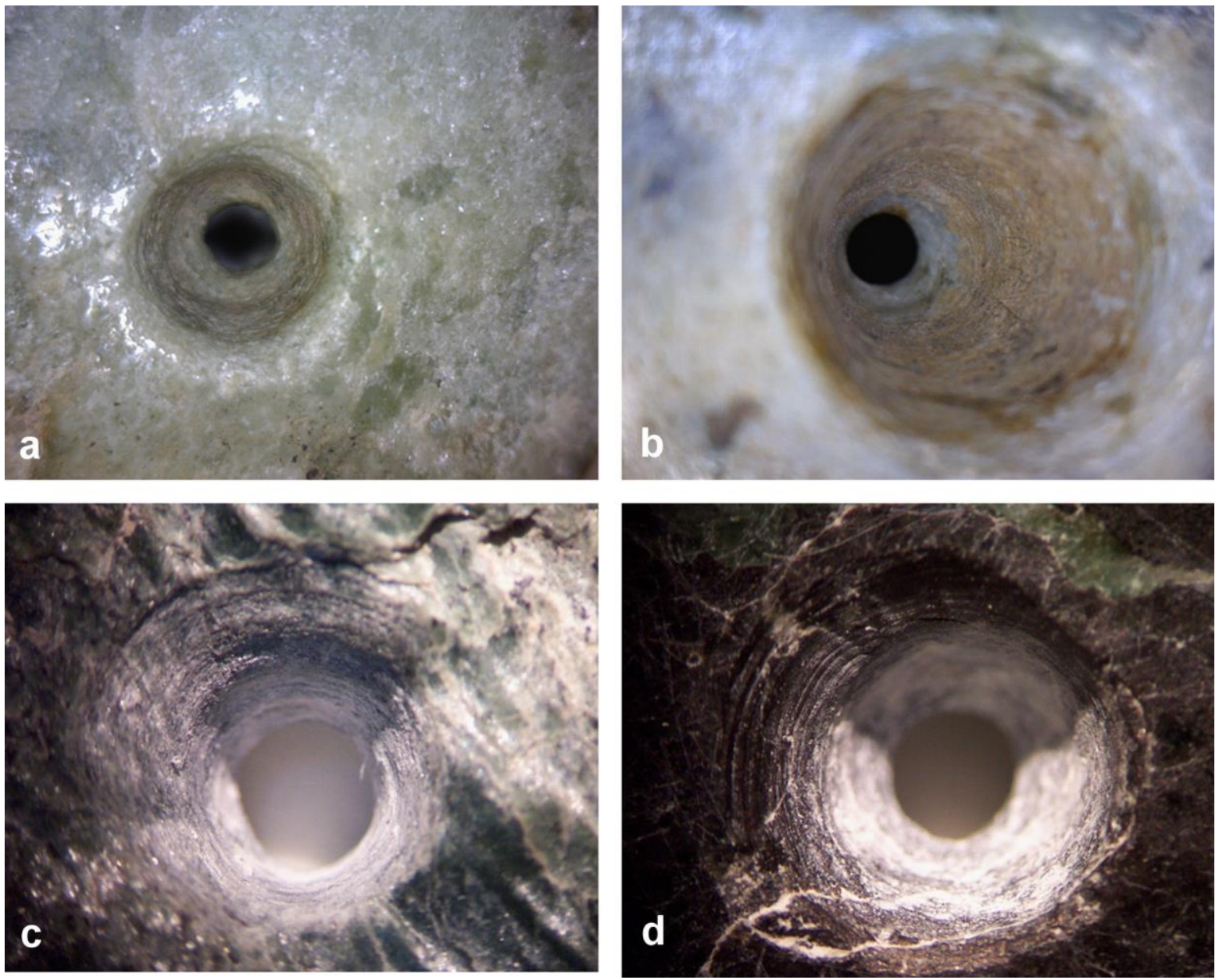

Figura 9. Horadaciones en cuentas ( $a$-b) y perforaciones experimentales con buril de obsidiana (c) y de pedernal (d).

A más amplificaciones se pudo observar en todas las piezas una superficie irregular con una gran cantidad de partículas y una imagen que asemeja hojuelas, así como también bandas del orden de 2-4 $\mu \mathrm{m}$ (Figura 10a), rasgos que coinciden con el empleo experimental de perforadores de pedernal (Figura 10b).
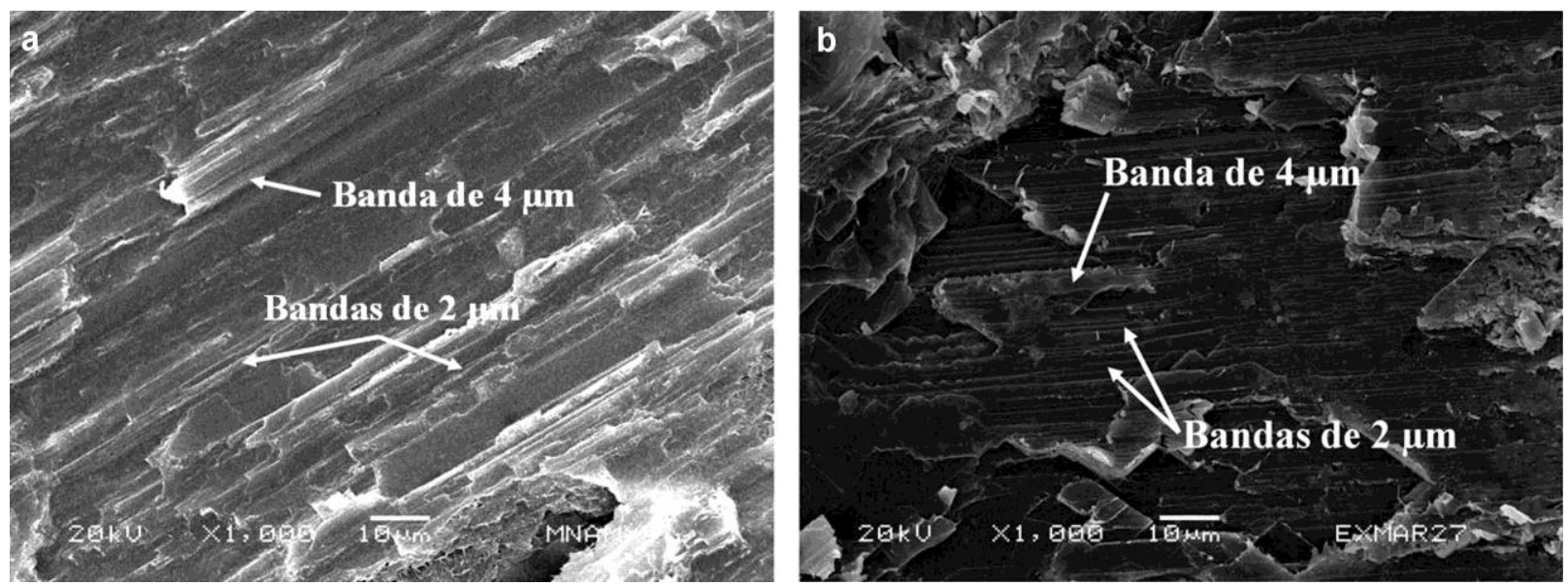

Figura 10. Perforación en cuenta (a) y horadación experimental con buril de pedernal (b). 


\subsection{El Volador}

El material lapidario recuperado en El Volador se caracteriza por seis cuentas y un pendiente de piedra verde. El análisis tecnológico indica que cinco cuentas y el pendiente presentan la misma tecnología, la cual corresponde a partir de su contrastación con procesos experimentales con desgaste con roca de andesita, pulido con nódulo de pedernal y horadación con perforador de pedernal. La única pieza que contrasta con ello es una cuenta, la cual presenta desgaste con caliza, pulido con nódulo de jadeíta y perforación con perforador de pedernal.

\subsubsection{Superficies y acabados}

Con microscopía óptica es posible apreciar en todas las piezas líneas rectas tenues y difusas, así como una superficie sumamente lustrosa (Fig. 11).
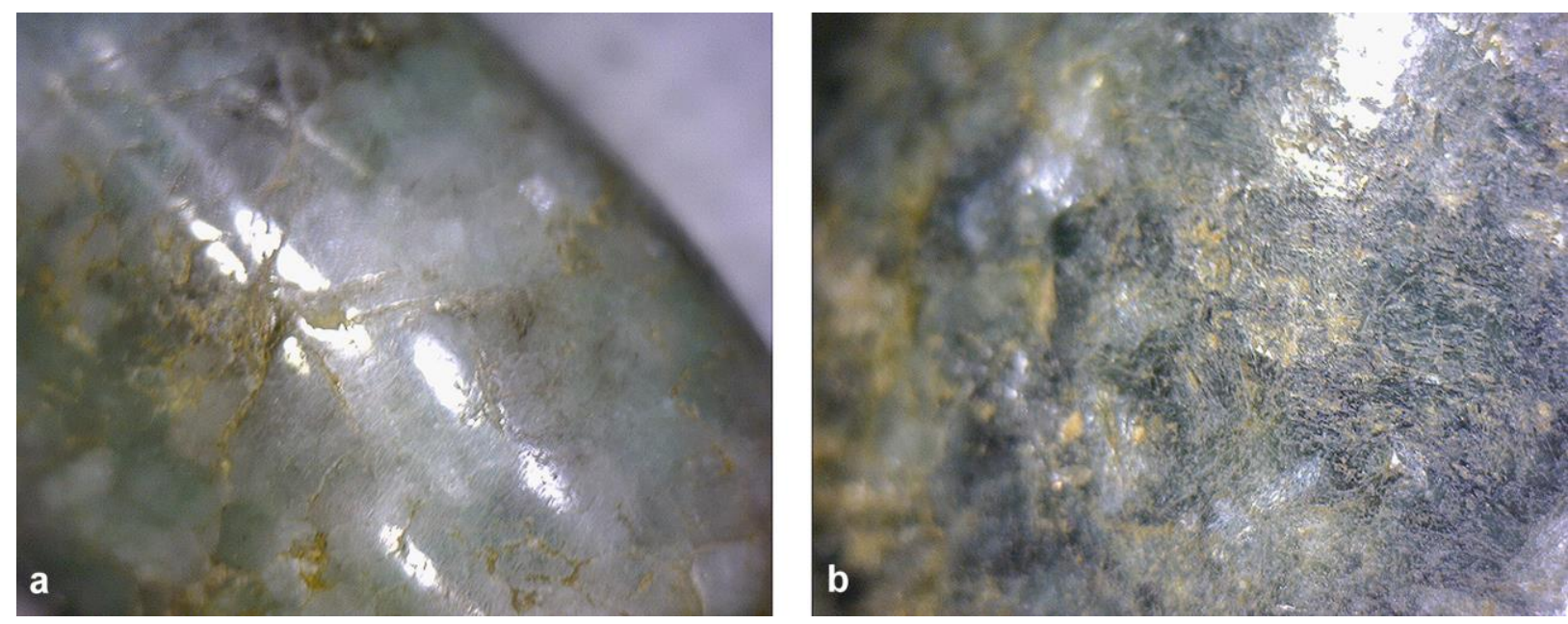

Figura 11. Superficie de cuentas a 10X (a) y $30 X(b)$.

Con MEB se identificaron dos patrones: en el primero se ven bandas rectas paralelas del orden de las $66 \mu \mathrm{m}$ principalmente (Fig. 12a), las cuales coinciden con el empleo experimental de lajas de andesita para desgastar y regularizar (Fig. 8b). El mismo rasgo visto a 1000X presenta bandas rectas paralelas bien marcadas de $2-4 \mu \mathrm{m}$ que corren en diversas direcciones sobre una superficie más o menos regular (Fig. 12b). Dicha característica coincide con el empleo de acabados con pulidor de pedernal (Fig. 8d). En cuanto al segundo patrón, solamente una cuenta lo presenta y se caracteriza por bandas rectas paralelas del orden de las $20 \mu \mathrm{m}$ (Figura 12c), las cuales corresponden al empleo experimental de lajas de caliza (Figura 7b). A 1000X se distingue una superficie con partículas y líneas rectas difusas de $1-2 \mu \mathrm{m}$ de grosor (Figura 12d), dicha característica corresponde al pulido experimental empleando nódulo de jadeíta (Figura 7d). 
R.B. Solís Ciriaco, E. R. Melgar Tísoc y B. Olmedo Vera. Análisis tecnológico de objetos lapidarios de la sala mexica dentro de la bóveda del Museo Nacional de Antropología, México.
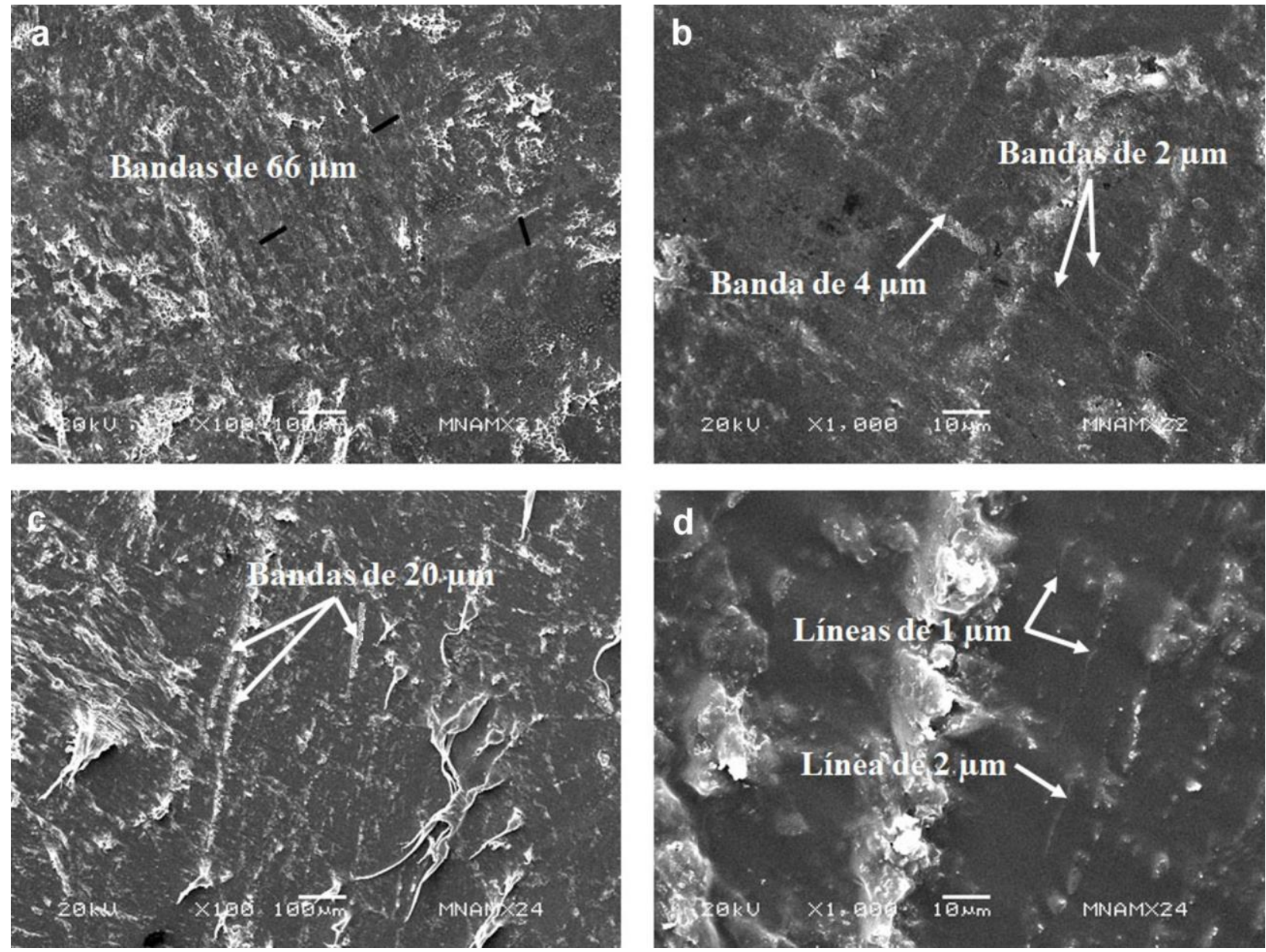

Figura 12. Análisis de cuentas: superficie (a) y acabado (b) en la que se identificó desgaste con laja de andesita y pulido con nódulo de pedernal; superficie (c) y acabado (d) en la que se detectó desgaste con lajas de caliza y pulido con nódulo de jadeíta.

\subsubsection{Perforaciones}

Las siete piezas de la colección presentan huellas de círculos concéntricos (Fig. 13), evidencia del empleo de perforadores líticos sólidos como buriles (Fig. 9c-d).
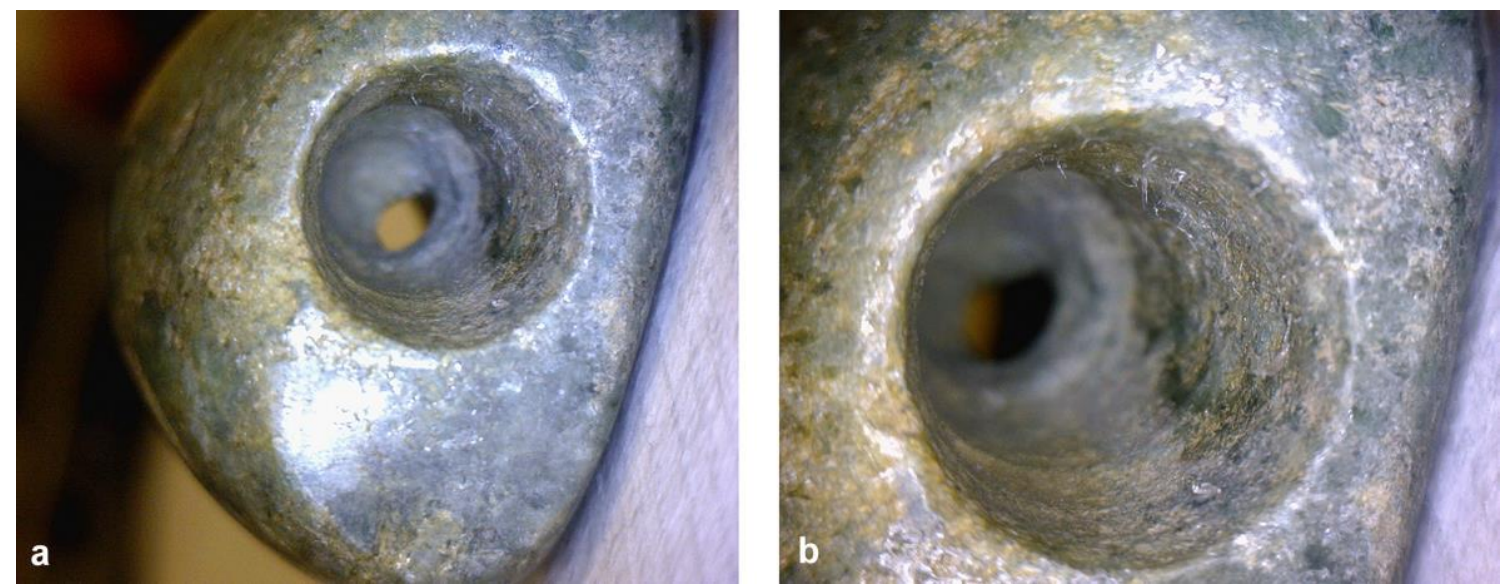

Figura 13. Perforación en cuenta a $10 X$ (a) y $30 X(b)$. 
En la misma modificación a 1000X es posible identificar bandas rectas del orden de $2-4 \mu \mathrm{m}$ sobre una superficie rugosa (Fig. 14a), dicho rasgo coincide con el empleo experimental de buril de pedernal para horadar piezas (Fig. 14b).
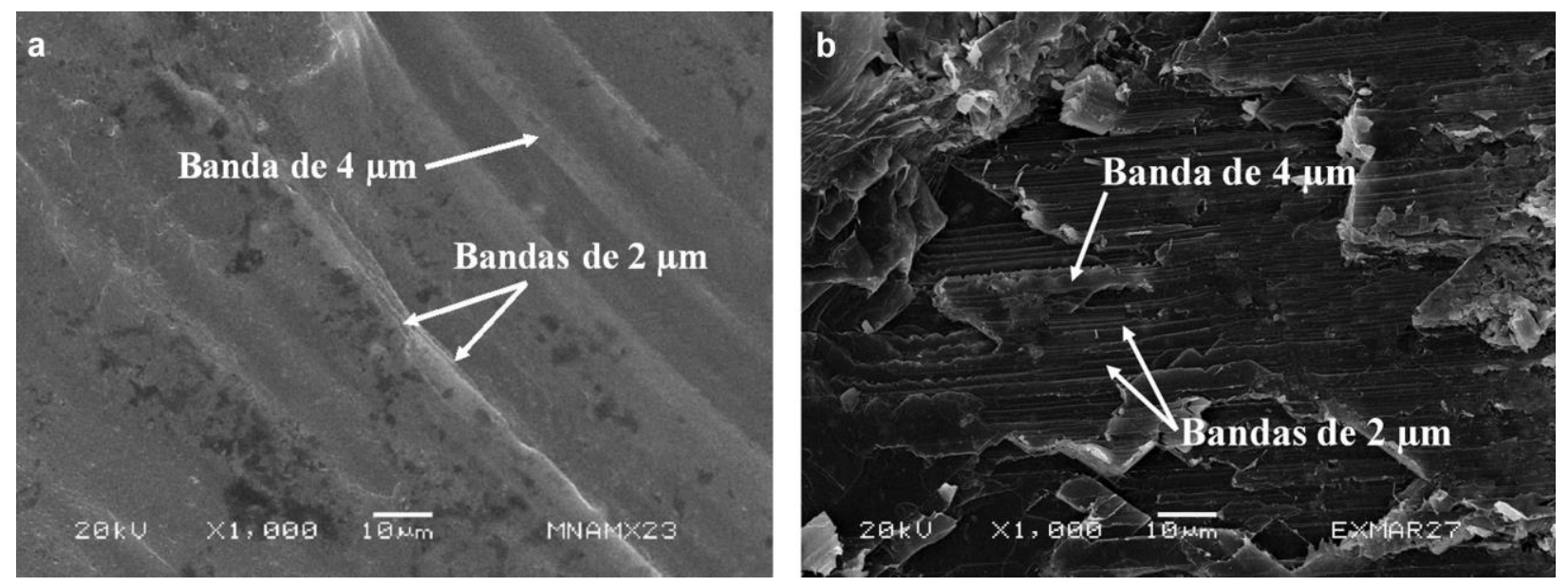

Figura 14. Perforación en cuenta (a) y horadación experimental hecha con buril de pedernal (b).

\subsection{Azcapotzalco}

La colección la forman cinco cuentas de piedra verde de distintas tonalidades que van del color crema, verde claro al verde oscuro, casi negro (Fig. 4). Cabe señalar que solo fue posible identificar la tecnología de tres cuentas. Dos cuentas de tonalidad verde oscuro y café presentan desgaste con roca caliza y acabados con nódulos de jadeíta. Una cuenta café oscuro tiene rasgos que coinciden con el empleo de riolita para desgastar y nódulo de pedernal para dar acabados.

\subsubsection{Superficies y acabados}

Las piezas presentan en sus superficies líneas finas y difusas y una superficie poco lustrosa (Fig. 15).
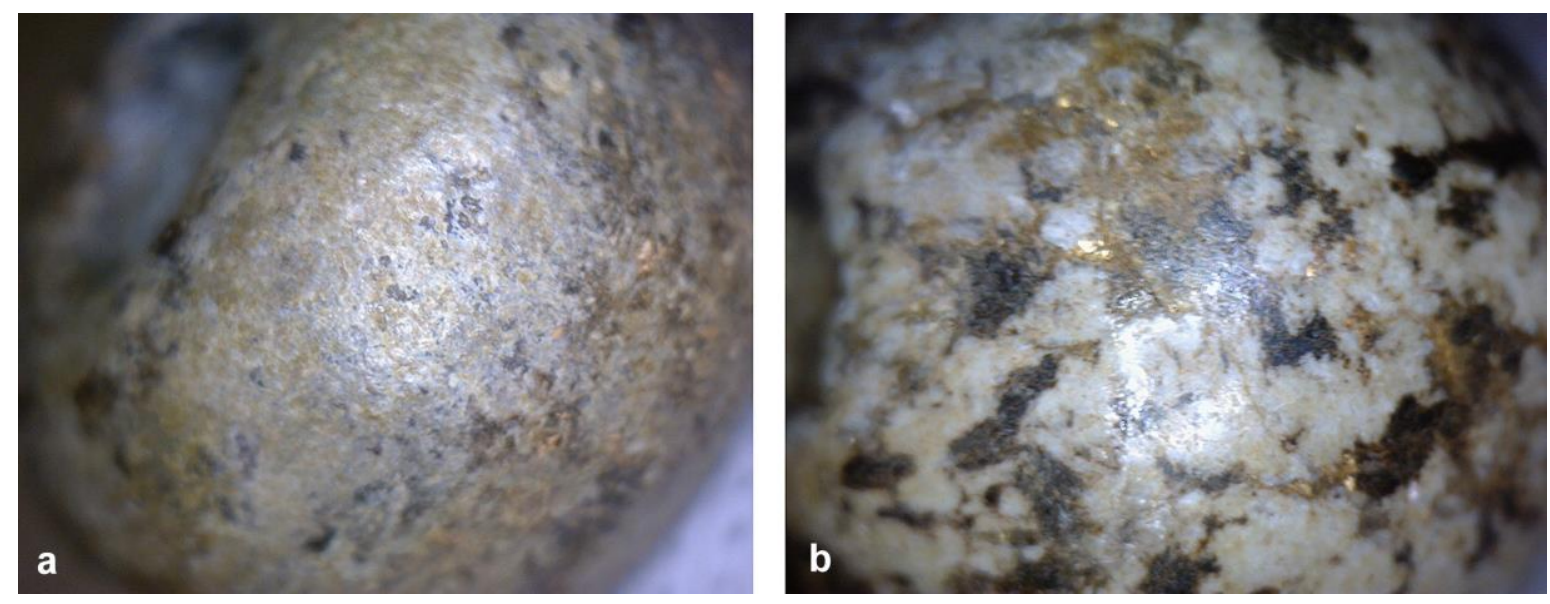

Figura 15. Superficies de cuentas.

Con MEB es posible detectar dos patrones. El primero y más frecuente son bandas del orden de las $20 \mu \mathrm{m}$ sobre una superficie rugosa (Fig. 16a), dicho rasgo coincide con el empleo de lajas de caliza para desgastar (Fig. 7b). A mayores amplificaciones se identificaron líneas rectas y difusas que van de 1-2 $\mu \mathrm{m}$ de grosor sobre una superficie con partículas (Fig. 16b), dicho rasgo coincide con el empleo de pulidor de jadeíta para dar acabados (Figura 7d). El patrón menos común, 
R.B. Solís Ciriaco, E. R. Melgar Tísoc y B. Olmedo Vera. Análisis tecnológico de objetos lapidarios de la sala mexica dentro de la bóveda del Museo Nacional de Antropología, México.

detectado en una sola cuenta, consiste en bandas del orden de las $33 \mu \mathrm{m}$ (Fig. 16c), el cual corresponde al uso de riolita para desgastar (Fig. 16d). A más aumentos se ven bandas rectas paralelas que van de $2-4 \mu \mathrm{m}$ de grosor (Fig. 16e), las cuales son similares a los rasgos experimentales producidos con el pulidor de pedernal (Fig. 16f).
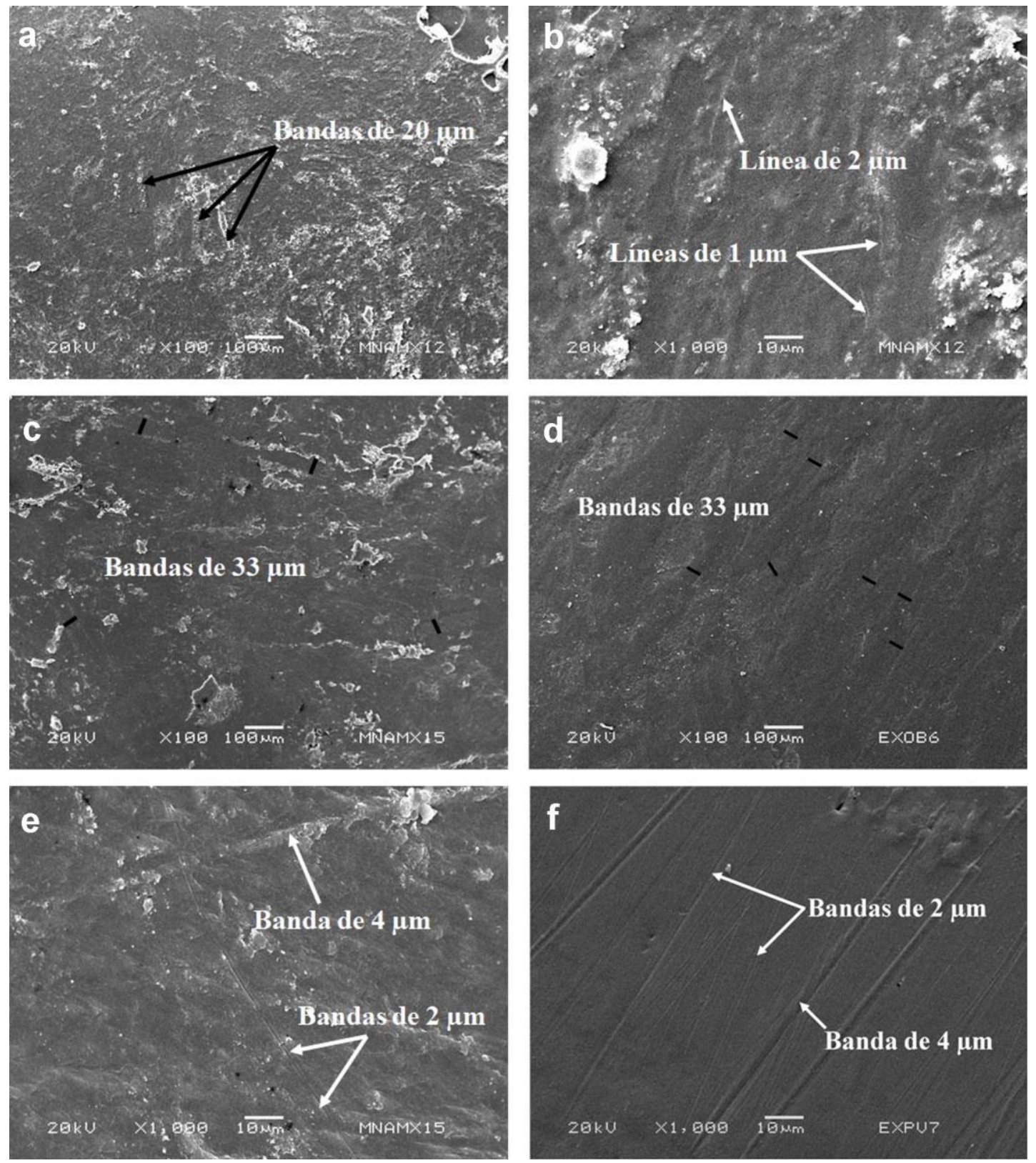

Figura 16. Cuentas arqueológicas: desgaste donde se identificó el empleo de caliza (a) y acabado en el que se detectó el empleo de nódulo de jadeíta $(b)$, superficie de cuenta $(c)$ en la que se detectó el desgaste experimental hecho con riolita (d) y acabado (e) que coincide con el empleo de pulidor de pedernal (f).

\subsubsection{Perforaciones}

En todas las cuentas de Azcapotzalco se aprecian círculos concéntricos (Fig. 17), evidencia del empleo de instrumentos líticos para hacer las horadaciones (Fig. 9c-d). 

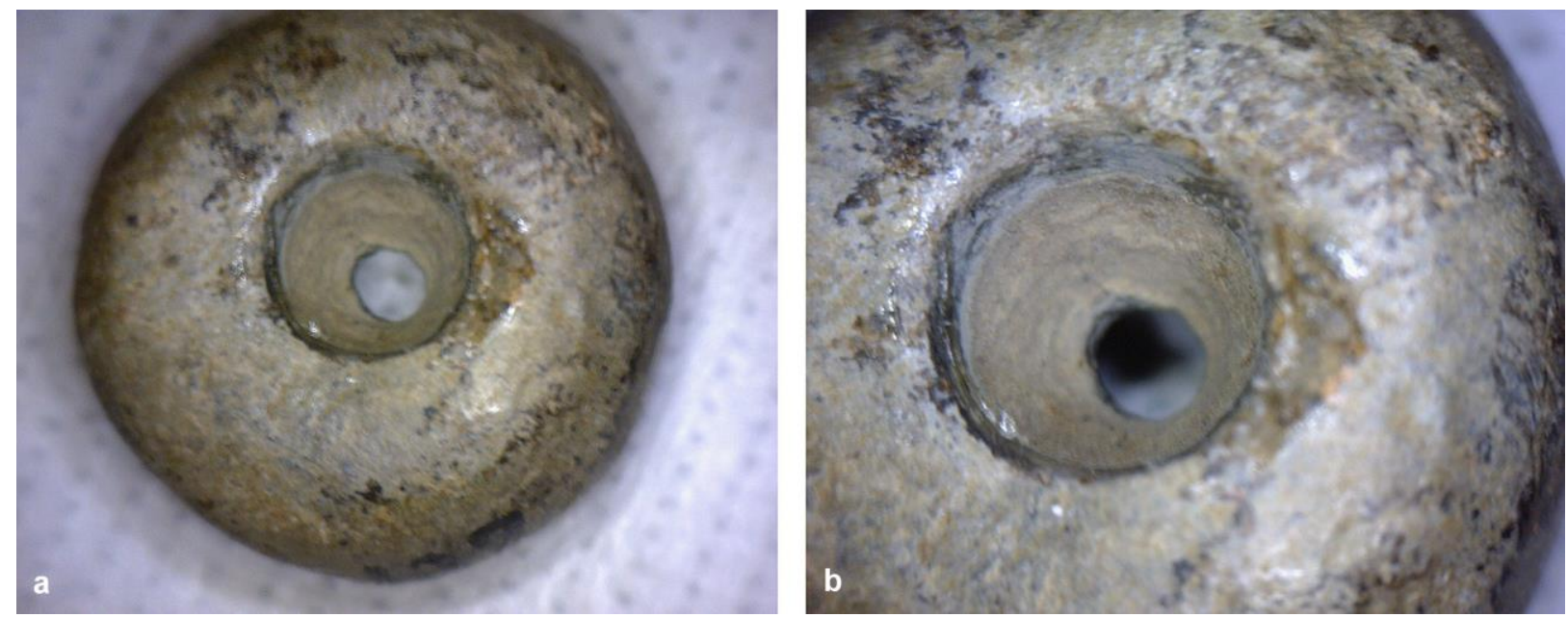

Figura 17. Perforación bicónica en cuenta a $10 X(a)$ y $30 X(b)$.

Con MEB fue posible identificar bandas rectas paralelas del orden de las 2-4 $\mu \mathrm{m}$ de grosor (Fig. 18), las cuales coinciden con las horadaciones experimentales con buriles de pedernal (Fig. 14b).
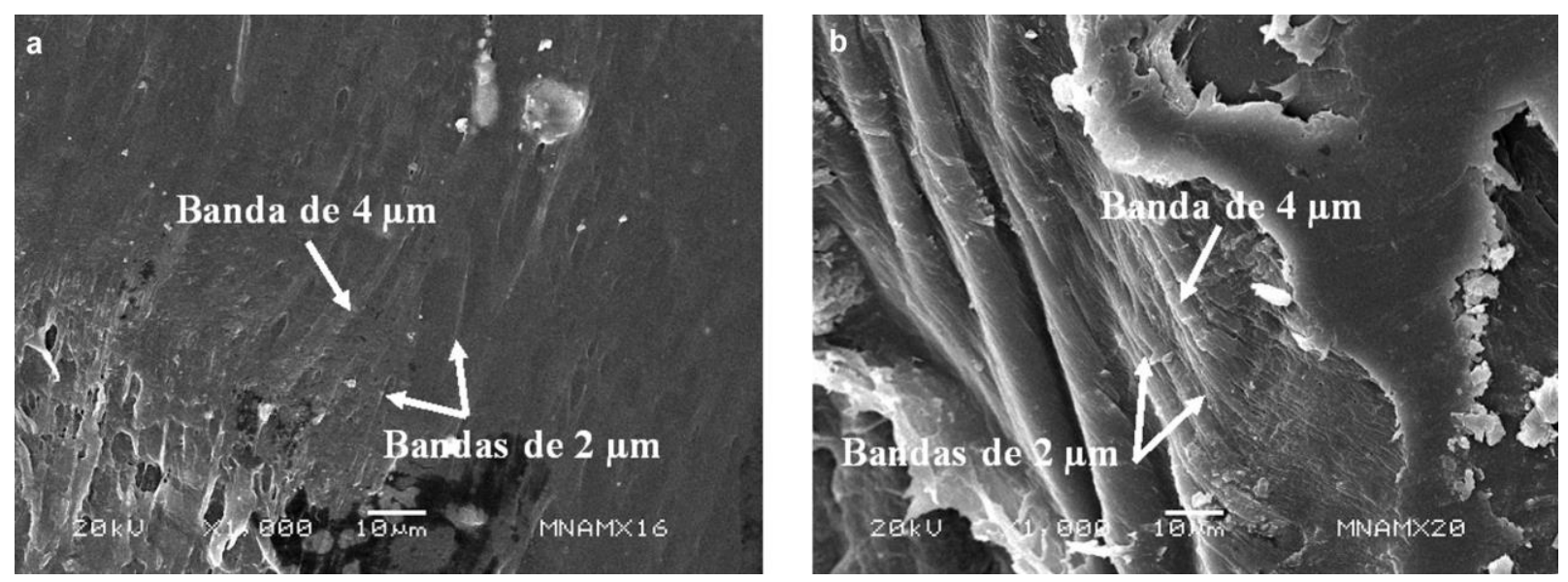

Figura 18. Horadaciones en cuentas.

La tecnología de las colecciones de Tlatelolco, El Volador y Azcapotzalco presentan tres tecnologías, la más frecuente tiene como principal indicador el desgaste con caliza y pulido con nódulo de jadeíta, le sigue el desgaste con andesita y pulido con pedernal, y en menor número el desgaste con riolita y pulido con pedernal (Tabla 5).

\begin{tabular}{|c|c|c|c|}
\hline \multicolumn{4}{|c|}{ Tabla 5. Tecnología de las colecciones } \\
\hline Colección & Desgaste & Perforación & Acabados \\
\hline Tlatelolco & Caliza/andesita & Pedernal & Jadeíta/pedernal \\
\hline El Volador & Andesita/caliza & Pedernal & Pedernal/jadeíta \\
\hline Azcapotzalco & Caliza/riolita & Pedernal & Jadeíta/pedernal \\
\hline
\end{tabular}

\section{DISCUSIÓN DE RESULTADOS}

A partir de los resultados anteriores podemos concluir que los objetos lapidarios recuperados en Tlatelolco, El Volador y Azcapotzalco presentan cierta estandarización en determinados 
elementos, mayoritariamente en cuentas de piedra verde, las cuales presentan una tecnología detectada para sitios del área maya. En dichas piezas se identificó el uso de caliza para desgastar y regularizar, buriles de pedernal para perforar y pulidores de jadeíta para dar acabados. Esta tecnología coincide con instrumentos de trabajo, en especial las lajas de caliza (Fig. 20), que han sido hallados en distintos talleres lapidarios del valle del río Motagua (Walters, 1989; Rochette, 2009:210-214), así como también en los asentamientos de Copán, Tikal, Calakmul y Cancuén (Fash, 1991:160; Moholy-Nagy, 1997:300-310; Domínguez y Folan, 1999: 643; Folan et al., 2001:252; Kovacevich, 2006:184-186; Widmer, 2009:188-197). Este patrón tecnológico se ha identificado en colecciones lapidarias analizadas con arqueología experimental de sitios mayas de las Tierras Bajas del Sur, como en Calakmul, Cancuén, La Corona, El Perú-Waká (Melgar y Andrieu, 2016) y en el ajuar de Pakal en Palenque (Melgar, 2017). También se ha detectado en estudios de reliquias procedentes del área maya encontradas en el Templo Mayor de Tenochtitlan (Solís, 2015; Melgar et al., 2018; Monterrosa, 2018). A partir de ello, se propone que dichos elementos fueron elaborados en el área maya, posiblemente en los talleres ubicados en el Motagua desde el periodo clásico; ya que las evidencias arqueológicas sugieren que, en estos sitios, se hacían las piezas más sencillas y sin diseños incisos (Rochette, 2009:216-217) como es el caso de los materiales bajo estudio.

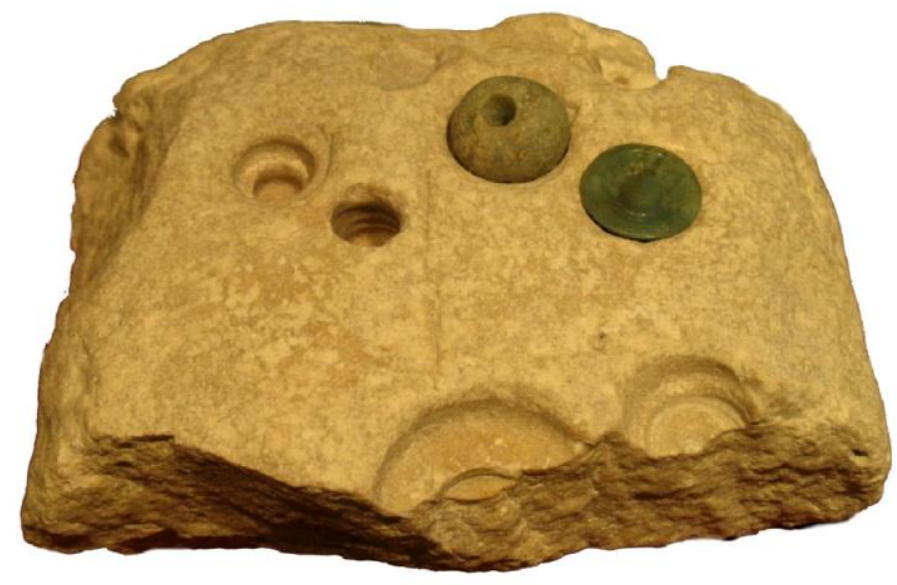

Fig. 19. Desgastador de piezas lapidarias en caliza. Fotografía de Emiliano Melgar.

Con base en los resultados y la experiencia de la revisión y análisis de diversas colecciones lapidarias recuperadas en el Altiplano Central, se puede determinar una circulación irrestricta de cuentas de piedra verde procedentes de la zona maya que fueron consideradas reliquias, muy probablemente producto del intercambio de otro tipo de bienes y materiales durante el periodo posclásico.

A su vez, la tecnología detectada en piezas elaboradas a partir del empleo de andesita para desgastar y regularizar, buriles de pedernal para perforar y pulidores del mismo material para dar acabados, coinciden con la tecnología empleada en colecciones lapidarias analizadas de varios sitios de Guerrero como Teopantecuanitlan y Oxtotitlan correspondientes al periodo Preclásico o Formativo (400 a.C.-150 d.C.), así como Pezuapan, Los Filos-Mezcala, El Bermejal y Carrizalillo (Monterrosa y Melgar, 2006) y La Organera-Xochipala, fechados para el periodo Epiclásico (600-900 d.C.). Dicha tecnología se ha detectado principalmente en piezas de piedra verde de formas geométricas y sencillas como hachas y cuentas. Ello permite proponer que estas 
piezas también pueden ser "reliquias" del que se ha denominado estilo Mezcala pero con legado tecnológico del periodo Formativo que perdura hasta el periodo Epiclásico (Solís, 2015).

En cuanto a la identificación de riolita para desgastar, buril de pedernal para perforar y nódulo de pedernal para dar acabados, este patrón corresponde a la tecnología identificada en el taller de lapidaria hallado en Xochimilco (Solís, 2019). Dicha información resulta muy interesante, ya que nos indica que probablemente las piezas con esta tecnología pudieron haber sido elaboradas en la región de Xochimilco en la parte sur de la Cuenca de México.

A partir de todo lo anterior podemos concluir que los bienes lapidarios analizados procedentes de Tlatelolco, El Volador y Azcapotzalco son mayoritariamente reliquias, cuya tecnología y procedencia puede ser de épocas tan tempranas como del periodo formativo. Dentro de esta temporalidad se encuentran las cuentas desgastadas con andesita, mientras que para el periodo clásico corresponderían las identificadas con caliza para desgastar. Tales reliquias pudieron venir con otros bienes procedentes de la región maya o de la zona de Guerrero, para ser intercambiadas dentro de las diversas redes de comercio de bienes de prestigio cuyo destino pudo haber sido el mercado de Tlatelolco. Con respecto a las piezas lapidarias desgastadas con riolita recuperadas en Azcapotzalco, resulta interesante que tal tecnología se ha detectado para el periodo posclásico en el taller lapidario de Xochimilco, lo que nos hace pensar que muy probablemente pudieron proceder de esa región, e intercambiada entre estos dos centros urbanos.

Para finalizar, en este estudio se mostró la riqueza de información que se puede obtener de los análisis tecnológicos de las huellas de manufactura. En el caso de las piezas analizadas, la caracterización e identificación de los materiales empleados en su elaboración pudo realizarse satisfactoriamente, debido a que el estado de conservación de los objetos era muy bueno y a que los trazos de los instrumentos empleados no fueron borrados por deterioros o abrasiones postdeposicionales. Sin embargo, existen casos de piezas de otras colecciones que no están en buenas condiciones y ello dificulta este tipo de análisis, por lo cual, el estado de conservación es un factor importante en estos estudios. En cuanto a los posibles desgastes postdeposicionales, esto es más común en materiales de superficie o contextos sometidos a procesos erosivos, por lo cual se deben comparar los trazos generados por la abrasión de arena u otro sedimento con las huellas para descartar posibles palimpsestos o traslapes de huellas culturales y naturales.

\section{Agradecimientos}

Este trabajo no hubiera sido posible sin el apoyo de Ciencia Básica CONACYT CB-283896 y del proyecto posdoctoral "La lapidaria en la Cuenca de México: estilos tecnológicos y escuelas artesanales durante el período Posclásico" para poder desarrollar las actividades y la colaboración interinstitucional entre varios laboratorios del INAH y la UNAM, así como al permiso del Consejo de Arqueología para autorizar estos análisis en colecciones lapidarias. También fue importante la colaboración de Mario Monroy del Laboratorio de Microscopía Electrónica del INAH y de los integrantes del taller de arqueología experimental en lapidaria: Hervé Monterrosa, Edgar Pineda, Viridiana Guzmán, Laura Carrillo, Andrea Pérez, Angy Domínguez, Adriana Soto, Francisco Macedo y Marcos Reyes. De igual forma el acceso al acervo de la Sala Mexica resguardado en la Bóveda del Museo Nacional de Antropología no hubiera podido hacerse sin los permisos y facilidades otorgadas por Laura del Olmo, subdirectora de arqueología de ese museo. 
R.B. Solís Ciriaco, E. R. Melgar Tísoc y B. Olmedo Vera. Análisis tecnológico de objetos lapidarios de la sala mexica dentro de la bóveda del Museo Nacional de Antropología, México.

\section{Bibliografía}

ASCHER, R. (1961): “Experimental Archaeology”, American Anthropologist, 63(4):793-816.

BINFORD, L. R. (1991): Bones, ancient men, and modern myths, Academic Press, London.

CHARLTON, C. O. (1993): "Obsidian as Jewelry: Lapidary production in Aztec Otumba, Mexico", Ancient Mesoamerica, 4:231-243

DOMÍNGUEZ CARRASCO, M. R. y W. J. FOLAN (1999): “Hilado, confección y lapidación: los quehaceres cotidianos de los artesanos de Calakmul, Campeche, México". En J. P. Laporte y H. L. Escobedo (eds.): XII Simposio de Investigaciones Arqueológicas en Guatemala, 1998, pp. 628-646, Museo Nacional de Arqueología y Etnología, Guatemala.

DURÁN, D. (2006): Historia de las Indias de Nueva España e Islas de Tierra Firme, Porrúa, México.

FASH, W. (1991): Scribes, Warriors and Kings. The City of Copan and the Ancient Maya, Thames and Hudson, London.

FEINMAN, G. M. y L. M. Nicholas (1995): "Household Craft Specialization and Shell Ornament Manufacture in Ejutla, Mexico", Expedition, 37(2):14-25.

FOLAN, W. J., J. D. GUNN y M. R. DOMÍNGUEZ CARRASCO (2001): “Triadic Temples, Central Plazas and Dynastic Palaces: A Diachronic Analysis of the Royal Court Complex, Calakmul, Campeche, Mexico”. En T. Inomata y S. D. Houston (eds.): Royal Courts of the Ancient Maya. Volume Two: Data and Case Studies, pp. 223-266, Westview Press, Oxford.

HODDER, I. (2016): Studies in Human-Thing Entanglement, Nueva Jersey, Wiley-Blackwell.

KOVACEVICH, B. (2006): Reconstructing Classic Maya Economic Systems: Production and Exchange at Cancuen, Guatemala, Tesis de Doctorado en Filosofía, Vanderbilt University, Nashville.

LECHTMAN, H. (1977): "Style in Technology, Some Early Thoughts". En: Material Culture: Styles Organization, and Dinamics of Technology, pp. 3-20, West Publishing, New York.

MELGAR TÍSOC, E. R. (2014): Comercio, tributo y producción de las turquesas del Templo Mayor de Tenochtitlan, Tesis de Doctorado en Antropología, UNAM, México.

MELGAR TÍSOC, E. R. (2017): "Manufacturing techniques of the greenstone mosaics from Teotihuacan and Palenque". En Playing with the time. Experimental archaeology and the study of the past, pp. 119-124. Universidad Autónoma de Madrid, Madrid.

MELGAR TÍSOC, E. R. y C. ANDRIEU (2016): "El intercambio del jade en las Tierras Bajas Mayas, desde una perspectiva tecnológica". En: XXIX Simposio de Investigaciones Arqueológicas de Guatemala, pp. 1065-1076, Museo Nacional de Arqueología y Etnología, Guatemala. 
MELGAR TÍSOC, E. R., R. B. SOLÍS CIRIACO y H. V. MONTERROSA DESRUELLES (2018): Piedras de fuego y agua: turquesas y jades entre los nahuas, México, Museo del Templo Mayor/INAH-Museo de Geología/UNAM.

MIRAMBELL, L. (1968): Técnicas Lapidarias Prehispánicas, INAH, México.

MOHOLY-NAGY, H. (1997): "Middens, Construction Fill, and Offerings: Evidence for the Organization of Classic Period Craft Production at Tikal, Guatemala", Journal of Field Archaeology, 24:293-313.

MONTERROSA DESRUELLES, H. V. (2018): La presencia maya en el Templo Mayor de Tenochtitlan. El Análisis tecnológico de los objetos de jadeíta verde imperial, Tesis de doctorado en Arqueología, ENAH, México.

MONTERROSA DESRUELLES, H. V. y E. R. MELGAR TÍSOC (2006): "Tecnología de cuentas en piedra caliza del área Mezcala, Guerrero", Tecuani. Boletín del Centro INAHGuerrero, 2(7):4-6.

ROCHETTE, E. T. (2009): "Jade in Full: Prehispanic Domestic Production of Wealth Goods in the Middle Motagua Valley, Guatemala". En K. G. Hirth (ed.): Housework: Craft Production and Domestic Economy in Ancient Mesoamerica, pp. 205-224, American Anthropological Association, New Jersey.

SAHAGÚN, B. (2006): Historia General de las Cosas de Nueva España, Porrúa, México.

SOLÍS CIRIACO, R. B. (2015): Esferas de Producción y consumo de los objetos lapidarios en las estructuras aledañas del Templo Mayor de Tenochtitlan, Tesis de Doctorado en Antropología, UNAM, México.

SOLÍS CIRIACO, R. B. (2019): Informe segundo semestre correspondiente al proyecto "La lapidaria en la Cuenca de México: estilos tecnológicos y escuelas artesanales durante el período Posclásico". Documento entregado al Archivo del Museo del Templo Mayor, INAH, México.

VELÁZQUEZ CASTRO, A. (2007): La producción especializada de los objetos de concha del Templo Mayor de Tenochtitlan, INAH, México.

WALTERS, R. (1989): “Un taller de jade en Guaytán, Guatemala”. En M. Gaxiola y J. E. Clark (coords.): La Obsidiana en Mesoamérica, pp. 253-262, INAH, México.

WIDMER, R. J. (2009): "Elite Household Multicrafting Specialization at 9N8, Patio H, Copan". En K. G. Hirth (ed.): Housework: Craft Production and Domestic Economy in Ancient Mesoamerica, pp. 174-204, American Anthropological Association, New Jersey. 